\title{
- $\sqrt{ }$ \\ IJCRR Section: Healthcare \\ Sci. Journal Impact Factor \\ ICV: 71.54 \\ Prevalence of Risk Factors for Diabetes Among Construction Workers in Majmaah City, Saudi Arabia
}

\section{Mohammad Shakil Ahmad}

\author{
Assistant Professor (Community Medicine), College of Applied Medical Science, Qassim University, Kingdom of Saudi Arabia
}

\section{ABSTRACT}

Background: Considering the fact that diabetes is one of the most prevalent non - communicable diseases in the world today, secondary prevention can at best prolong life of those affected by it. But arguably it has been proved time and again that primary prevention will always lead to a better quality of life. Risk factors have been the major factors studied worldwide to prevent diabetes and due to a high rate of migration of people around the world it should be considered as an essential tool to diagnose the risk of diabetes among migrants.

Purpose: The aim of the study was to assess the risk factors that play a significant role in causing diabetes among construction workers.

Methods: The risk factors data was collected from 120 (150) construction workers (response rate=80\%) staying in two residential compounds. The workers were asked to fill in a pre - tested, structured and close-ended questionnaire to evaluate the risk factors. In addition, we measured the BP and BMI by using weight scale, measuring tape, and mercury sphygmomanometer.

Results: The results showed that construction workers had an acceptable quality of life but the risk factors were also present that could pose a threat in future to the development of diabetes mellitus. $95.5 \%$ ate all types of food without any consideration. $21.7 \%$ of them were above the normal weight. $62.5 \%$ were sleeping less than 7 hours, which increased the stress level.

Conclusions: Construction workers have good quality of life in Saudi Arabia. However, prevalence of modifiable and nonmodifiable risk factors for developing DM is considerable. Primary preventive measures need to be inculcated to reduce it to a level where it ceases to be a public health problem.

Key Words: Expatriates, Asians, Risk factors, Diabetes mellitus, Saudi Arabia

\section{INTRODUCTION}

Diabetes mellitus is a chronic metabolic disorder, which has affected all part of the world, and its prevalence is still increasing. The people living with diabetes are vulnerable to various complications both long term and short term.

According to WHO more than one in three adults worldwide has diabetes - a condition that causes around half of all deaths from stroke and heart disease. It has also published that that 347 million people worldwide have diabetes out of which more than $80 \%$ of people with diabetes live in lowand middle-income countries with a grim projection that diabetes death will double between 2005 and 2030. ${ }^{2}$ It is important to note that diabetes is a multifactorial disorder, which is common in genetically susceptible individuals who are, exposed to environmental risk factors especially those who are employed in stressful and difficult environment condition.

Saudi Arabia is one of the largest labor markets in the world with 11 million foreign workers from more than 100 countries work in different sectors and fields. Saudi Arabia is committed to achieve the milestone of Vision 2030 and all efforts are being aimed at making labor market more attractive to foreign workers.

With the globalization of oil and gas industry Saudi Arabia has become an important work destination for many expatriate workers from various countries. Among expatriate workers, common health problems include alcoholism and

\section{Corresponding Author:}

Dr. Mohammad Shakil Ahmad (MBBS, MD), Assistant Professor (Community Medicine), College of Applied Medical Science, Qassim University, Kingdom of Saudi Arabia; Email: docshak@qu.edu.sa

ISSN: 2231-2196 (Print)

Received: 24.12 .2017
ISSN: 0975-5241 (Online)

Revised: 15.01 .2018
Accepted: 04.02 .2018 
respiratory problems caused by sand and dust in the air a situation exacerbated by continuous construction work in most states.

There is lot of evidence available from Multiple studies in the past that there is a much higher prevalence of cardiovascular diseases risk factors among expatriates living in a foreign country compared to their own country of origin. There has been mention of few studies in the gulf region about workers health problems like urinary tract infections, hepatitis E infections, accidents and injuries etc. but very rarely any studies have covered health problems like diabetes mellitus among the expatriate workers.

Contributing to the above factors it has been determined that working in shift may itself be an independent risk factor for sleeping quality, diabetes and hypertension even in retired workers. Applicable intervention strategies are needed for prevention of sleep loss, diabetes, and hypertension for shift workers.

With this occupational and environmental background we felt there is a need to look into the risk factors for non communicable diseases especially diabetes mellitus among apparently healthy non - Saudi construction workers and assess their health behavior and habits that can determine their chances of having the disease in the future.

\section{Research Problem and Motivation:}

This was a baseline pilot study to find out the association of risk factors for diabetes and hypertension among the immigrants workers and their knowledge and attitude toward its prevention in Majmaah, KSA.

\section{Research Methodology}

It was a cross - sectional study of the prevalence of risk factors among the expatriate construction workers for diabetes and hypertension. It consists of two parts:

a. An interview based pre - tested close-ended questionnaire administered to the participants and the responses entered by the interviewee.

b. An anthropometric assessment to measure BMI and recording the blood pressure in an ambulatory position.

There were six residential compounds of construction companies in Majmaah where the expatriate workers were residing. Cluster sampling method was used to select two residential compounds for the study. Since this is a baseline study to find out the prevalence of risk factors for diabetes and hypertension among expatriate workers, a complete enumeration method was used to include all the resident workers (150) in the study who were residing in the selected residential compounds.

Total duration of the study was 6 months. The data collection took around 2 months to complete as planned.
Training was given to the data collectors on conducting the survey. A language translator was present during the survey to resolve any issue of communication gap between the investigators and the participants.

The data collected with the aid of:

a) A pre - tested, structured and close ended questionnaire was administered by the investigators to the study participants.

b) A human electric weighing scale calibrated to the nearest $0.5 \mathrm{kgs}$ used for taking weight.

c) A measuring tape - each $1 \mathrm{~cm} 10$ line 5 line mean 112 $\mathrm{cm}$ was used for measuring the height of the participants to calculate the BMI

d) A blood pressure instrument - calibrated to the nearest $0.5 \mathrm{~mm}$ of $\mathrm{Hg}$ used to take the blood pressure in the sitting position.

Data analysis was done using SPSS version 20.0 for assessing the qualitative data.

\section{- Ethical Considerations}

Participation consent from the workers was taken in the beginning of the study. They were briefed about the advantages to them as well as to the community due to their participation. All information kept purely confidential and to be used only for the purpose of statistical analysis.

\section{- Limitations}

- Due to difference in the mother tongue of the participants and the interview a slight probability of communication bias cannot be ruled out.

\section{- Inclusion and exclusion criteria}

- All the workers who are not citizens of Kingdom of Saudi Arabia were included in the study.

- Any study participants who voluntarily refused to participate in the study were excluded.

\section{RESULTS}

A total of 120 expatriates (70.6\%) participated out of a study sample of 170 residing in the residential compounds of a construction company in Majmaah, KSA. Most of the participants are native of Philippines, India and Pakistan. (Fig - 1)

The mean age of the participants was $35.25 \pm 8.78$ years. Most of them are married (76.7\%) but have left their family behind in their native countries. Even though majority of them are carpenters, there are 16 different occupations that the workers are involved in. Most of the workers come from a poor background (46.9\%) but almost $36.7 \%$ have finished their education till the secondary school while only $10 \%$ are illiterate $($ Table -1$)($ Table -3$)$ 


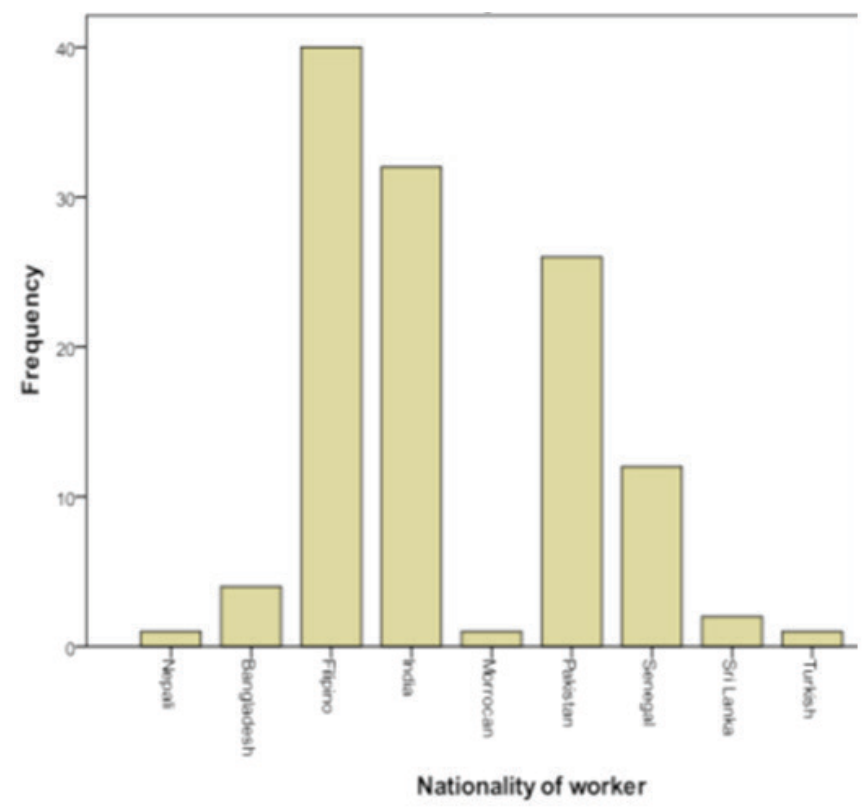

Figure 1: Nationality of the workers.

Table 1: Levels of education

\begin{tabular}{|l|l|}
\hline Level of education & Percentages \\
\hline Illiterate & $10 \%$ \\
\hline Primary & $11.7 \%$ \\
\hline Intermediate & $22.5 \%$ \\
\hline Secondary & $36.7 \%$ \\
\hline College & $19.2 \%$ \\
\hline
\end{tabular}

An analysis of the modifiable and non-modifiable risk factors was done from the data collected and it was found that most of them are at risk of diabetes and hypertension.

It was found that $28.3 \%$ of the study populations were more than 40 years old and at an increased risk though the family history for the presence of diabetes and hypertension was not significant.

An analysis of the dietary habit showed that even though almost all of them prefer to have homemade food, the regular intake of fruits and vegetables is abysmally low at $4.2 \%$. The dietary habit as shown in (Table 2)

Table 2: The dietary habits

\begin{tabular}{llc} 
& Type of diet & Frequencies \\
A & All & $95.8 \%$ \\
& Fruits and vegetables & $4.2 \%$ \\
B & Home food & $92.5 \%$ \\
& Outside food & $0.8 \%$ \\
& Both & $6.7 \%$ \\
\hline
\end{tabular}

Looking into the lifestyle preferences of the study participants it was found that $69.2 \%$ did exercises like brisk walking on a regular basis while the rest either were irregular or didn't do any at all. (Table - 4)

Majority of them were either tea or coffee drinkers $(92.5 \%)$ while more than half $(58.3 \%)$ consumed aerated drinks on a regular basis. About $12.5 \%$ had a history of alcohol consumption in the past. It was also found that more than $22 \%$ of the participants smoke on a regular basis. (Fig - 2) The average duration of sleep for most of the participants $(62.5 \%)$ was less than the recommended minimum of 7 hours per day for keeping good health. (Table - 3)

On calculating the basal metabolic index (BMI) it was found that more than $21 \%$ were in the overweight and obese category. (Fig. 3) Even the waist circumference (mean 90.27 \pm 9.5 $\mathrm{cm}$ ) among the $42.5 \%$ participants was more than the recommended $90 \mathrm{~cm} .{ }^{35}$ These are indicative of at risk population for diabetes and hypertension.

The measurement of blood pressure showed that more than $26.5 \%$ of the participants were having a high normal systolic reading $(120-139 \mathrm{~mm} \mathrm{Hg})$ while $19.2 \%$ recorded more than $140 \mathrm{~mm}$ of $\mathrm{Hg}$. Similarly, 33.3\% had a diastolic blood pressure reading of more than $90 \mathrm{~mm}$ of $\mathrm{Hg}$. A sizeable number of participants $(19.2 \%)$ had a high normal diastolic reading between $80-89 \mathrm{~mm}$ of $\mathrm{Hg}$. This is based on the classification given by the Joint National Committee; USA. ${ }^{36}$

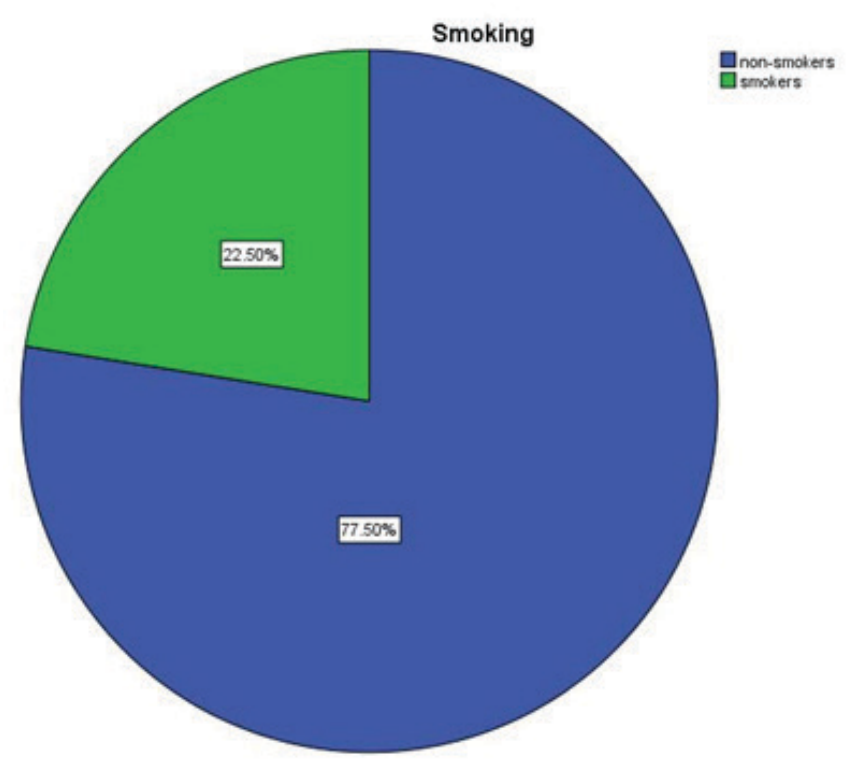

Figure 2: Smoking Habits. 


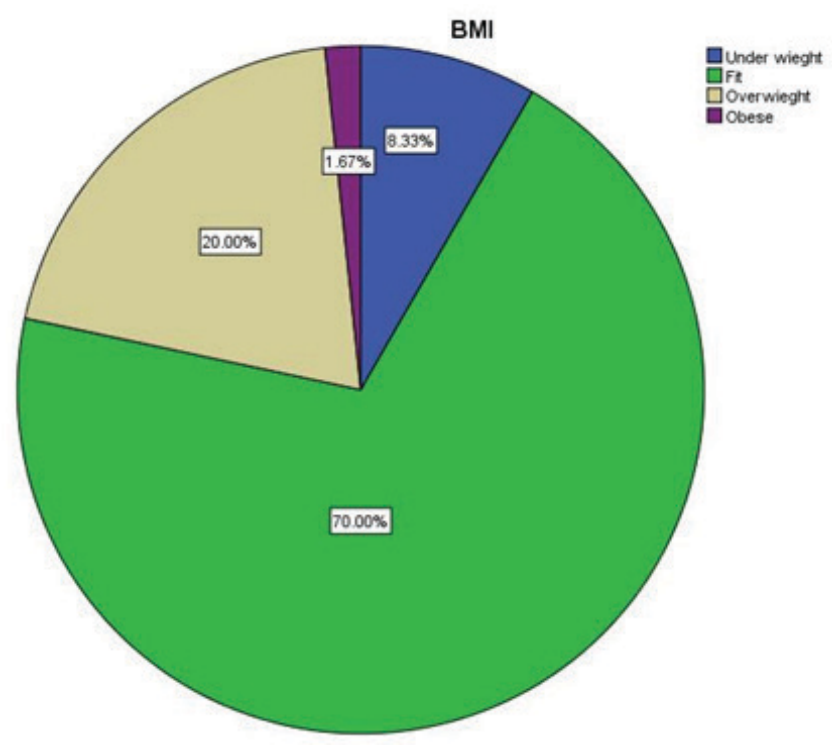

Figure 3: Basal Metabolic Index.

Table 3: Marital status, socio-economic status \& History of past illness

\begin{tabular}{cccc} 
Marital Status (\%) & \multicolumn{2}{c}{ Socio - economic status (\%) } \\
Married & 76.7 & Manual skilled & 46.9 \\
Single & 23.3 & Semi - skilled & 41.6 \\
& & Non manual & 9.7 \\
& & Others & 1.8
\end{tabular}

History of past illness or medication

History of Diabetes Mellitus History of Hypertension (\%) (\%)

\begin{tabular}{cccc} 
Yes & 1.7 & Yes & 2.9 \\
No & 98.3 & No & 97.1 \\
\hline
\end{tabular}

Table 4: Lifestyle Preferences

\begin{tabular}{lccc}
\multicolumn{4}{c}{ Lifestyle preferences } \\
Smoking (\%) & \multicolumn{3}{c}{ Chewing tobacco (\%) } \\
Yes & 22.5 & Yes & 10.8 \\
No & 77.5 & No & 89.2
\end{tabular}

\begin{tabular}{lccc} 
H/o alcohol intake (\%) & \multicolumn{3}{c}{$\begin{array}{c}\text { Drinking tea and/or cof- } \\
\text { fee (\%) }\end{array}$} \\
Yes & \multicolumn{3}{c}{ Yes } \\
No & 12.5 & Yes & 92.5 \\
& 87.5 & No & 7.5
\end{tabular}

Consume aerated drinks (\%) Doing regular exercise

(\%)

$\begin{array}{llll}\text { Yes } & 58.3 & \text { Yes } & 69.2 \\ \text { No } & 41.7 & \text { No } & 30.8\end{array}$

\author{
Duration of sleep (\%) \\ Less than 7 hours $\quad 62.5$ \\ More than 7 hours $\quad 37.5$
}

\section{DISCUSSION}

Analysis of the data shows that on average the expatriates have a good quality of life during their stay in Saudi Arabia with easy access to basic amenities like food, clothing and proper accommodation. Furthermore, since they don't find the local food acceptable, they prepare the food themselves when they are back from work. This study has shown that there is a significant proportion of expatriates who have non-modifiable and modifiable risk factors for diabetes and hypertension.

The results have shown that more than $28.3 \%$ of the study population was aged more than 40 years which according to other studies ${ }^{37}$ is one of the non - modifiable risk factors for developing diabetes and hypertension. The total number of participants with a positive family history was not significant which was in contrast to other studies ${ }^{38,39,40}$ that showed a positive correlation between family history and the risk of getting diabetes and hypertension.

Lots of literatures have discussed the harmful effects of smoking and significantly its association with developing cardiovascular diseases among chronic smokers. Thus, there is documentation of a direct causal association between smoking and diabetes ${ }^{41,42}$ and this study showed that more than $22.5 \%$ of the participants were smokers.

Dietary habit has significantly contributed single handedly to lifestyle diseases both in developed and developing countries. In our study we found that $95.8 \%$ of participant ate all types of food while very few took fruits and vegetables in substantial amount for health benefits. Similar studies have indicated that most of the people who consumed non - vegetarian food are at increased risk of diabetes and hypertension. ${ }^{43,44}$

The prevalence of overweight among the participants was $20 \%$ and around $1.7 \%$ was found to be obese. Many studies $^{45}$ have cited a direct association between obesity and non-communicable diseases like diabetes and hypertension. Our study showed that there was little awareness among the expatriate workers regarding obesity being a risk factor for diabetes and hypertension. A significant number of participants $(42.5 \%)$ had waist circumference above $90 \mathrm{~cm}$ which is a risk factor for cardiovascular diseases as given by the WHO. ${ }^{46}$

An assessment of the frequency of doing physical activity among the expatriates showed that around $30.8 \%$ were not 
exercising even for a minimum of 3 days a week as suggested by the $\mathrm{WHO}^{47}$ to maintain a healthy lifestyle. This showed that they were at increased risk of developing chronic health disorders as supported by similar articles showing this association $^{48}$

In study done in Guangzhou, China the prevalence estimate of self-reported NCDs was $16.0 \%$. Hypertension and diabetes were reported as the most important NCDs. Of those who responded, $6.8 \%$ reported having more than 2 chronic conditions. Since 2002, the prevalence of hypertension has decreased by $13.3 \%$. Awareness, treatment, and control of hypertension and diabetes were improved. The estimated prevalence of current smoking decreased, and the prevalence of former smoking increased from 2002. However, the prevalence of overweight and obesity, especially central obesity, increased. ${ }^{49}$

In a study done in Arab world in 2010, the burden of Disease Study 2010, the burden of non-communicable diseases (cardiovascular disease, cancer, chronic lung diseases, and diabetes) in the Arab world has increased, with variations between countries of different income levels. Behavioral risk factors, including tobacco use, unhealthy diets, and physical inactivity are prevalent, and obesity in adults and children has reached an alarming level. Despite epidemiological evidence, the policy response to non-communicable diseases has been weak. ${ }^{50}$

\section{CONCLUSION}

The magnitude of risk factors for chronic non-communicable diseases is quite high in the study population. Appropriate preventive measure should be taken to control and prevent risk factors that increase the prevalence of HTN and DM.

\section{Recommendation}

To reduce the prevalence of non-communicable diseases among expatriates working in an alien environment, preventive measures that need to be in place are:

- Regular medical checkup for the workers especially who have risk factors.

- Health promotion programs for the workers.

- Promote balanced healthy diet with regular exercise.

- Educational programs about the HTN and DM.

\section{REFERENCES}

1. http://www.who.int/features/qa/82/en/ (assessed on 04.12.2014)

2. http://www.who.int/diabetes/en/ (assessed on 04.12.2014)

3. Cox R, Jeremijenko A, Doig KM. Expatriate health and welfare: the hidden costs of getting it wrong. Society of Petroleum Engineers Asia Pacific Health, Safety, and Security Environment Conference and Exhibition, 10-12 September 2007, Bangkok, Thailand (http://www.onepetro.org/mslib/servlet/
onepetropreview?id=SPE-108547-MS, accessed 29 May 2013).

4. Fasano U, Iqbal Z. GCC countries: from oil dependence to diversification. Washington DC, International Monetary Fund, 2003:16-17.

5. http://www.arabnews.com/news/467423 (assessed on 04.12.2014)

6. Living and Working in Gulf States \& Saudi Arabia; http://www. justlanded.com/english/Saudi-Arabia/Saudi-Arabia-Guide/ Health/Introduction; (assessed on 04.12.2014)

7. Rahman H, Razzak MA, Chanda BC, Bhaskar KR, Mondal D; Cutaneous leishmaniasis in an immigrant Saudi worker: a case report; J Health PopulNutr. 2014 Jun;32(2):372-6.

8. F.M. Alswaidi, Z.A. Memish, R.F. Al-Hakeem and S.A. Atlam; Saudi Arabian expatriate worker fitness - screening programme: a review of 14 years of data; Eastern Mediterranean Health Journal; Vol. 19 No. $7 \cdot 2013 ; 664-670$

9. http://www.saudiembassy.net/about/country-information; accessed online on 05.12.2014

10. Akhtar S, Mohammed HGHH. Non linear pattern of pulmonary tuberculosis among migrants at entry in Kuwait; 1997 - 2006; BMC Public Health. 2008; 8:64

11. Al Khal AL, Bener A, Enarson DA; Tuberculosis among garment workers in an Arabian developing country: State of Qatar; Env\&Occ health. 2005, 60 (6): $295-298$.

12. Abu Madi MA, Bhenke JM, Ismail A, Patterns of infection with intestinal parasites in Qatar among food handlers and housemaids from different geographical regions of origin. Acta Trop. 2008; 106 (3): $213-20$

13. Ballal SG, Ahmed HO, Sebiany AM; Occupational health in Saudi Arabia; Occupational Medicine 2002 Jul-Sep;17(3):491-507, v-vi.

14. Faiza A. Qari; Pattern of thyroid malignancy at a University Hospital in Western Saudi Arabia; Saudi Medical Journal; Vol 25, No 7 (2004)

15. Elkum N1, Al-Arouj M, Sharifi M, Behbehani K, Bennakhi A.; Cardiovascular disease risk factors in the South Asian population living in Kuwait: a cross-sectional study; Diabet Med. 2014 May;31(5):531-9. doi: 10.1111/dme.12386. Epub 2014 Jan 22.

16. Chiu M1, Austin PC, Manuel DG, Tu JV; Comparison of cardiovascular risk profiles among ethnic groups using population health surveys between 1996 and 2007; CMAJ. 2010 May 18;182(8):E301-10. doi: 10.1503/cmaj.091676. Epub 2010 Apr 19

17. Cappuccio FP1, Cook DG, Atkinson RW, Strazzullo P.; Prevalence, detection, and management of cardiovascular risk factors in different ethnic groups in south London; Heart. 1997 Dec;78(6):555-63.

18. Cappuccio FP; Ethnicity and cardiovascular risk: variations in people of African ancestry and South Asian origin; J Hum Hypertens. $1997 \mathrm{Sep}$;11(9):571-6.

19. Agyemang C1, Bhopal RS; Is the blood pressure of South Asian adults in the UK higher or lower than that in European white adults? A review of cross-sectional data; J Hum Hypertens. 2002 Nov;16(11):739-51.

20. Misra A1, Khurana L.; The metabolic syndrome in South Asians: epidemiology, determinants, and prevention; Metab Syndr Relat Disord. 2009 Dec;7(6):497-514. doi: 10.1089/met.2009.0024.

21. Kannel WB, Sorlie P. Hypertension in Framingham. In: Paul O ed. Epidemiology and control of hypertension. New York: Stratton Intercontinental Medical Book Corp 1975;553-92.

22. Lewis CL, Russell RP. Risk factors for hyperension and cardiovascular disease in a changing Arabia. Saudi Med J 1985; 16:198-204.

23. Kahn, S. E., Hull, R. L. \&Utzschneider, K. M. Mechanisms link- 
ing obesity to insulin resistance and type 2 diabetes. Nature 444 , 840-846 (2006).

24. Nada A. Abahussain, PhD; Prevalence of intestinal parasites among expatriate workers in Al-Khobar, Saudi Arabia; Middle East Journal of Family Medicine, 2005; Vol. 3 (3)

25. Al-Rajeh S. Larbi E. Bademosi O. Awada A. Ismail H. AlFreihi H. Al-Ghassab G.; Stroke in a Tertiary Hospital in Saudi Arabia: A Study of 372 Cases; Eur Neurol 1991;31:251-256, (DOI:10.1159/000116685)

26. Ahmed H. Mitwalli, MD, FRCPE, FACP; Mohamed A. AlMaatouq, MD, MSc, FRCPC; Jamal Al-Wakeel, MD, FRCPC; Awatif A. Alam, MD, MSc; Hypercholesterolemia In Healthy Adult Males - A Public Survey In Central Saudi Arabia; Ann Saudi Med 1994;14(6):499-502

27. http://www.saudigazette.com.sa/index.cfm?method=home.Prin tContent\&action $=$ Print\&contentID $=0000000039661$. Accessed on the web on 8 January 2015.

28. Dirk Deleu, Ayman A. Hamad, Saadat Kamram, Abbas El Siddig, Hassan Al Hail, Samir M.K. Hamdy; Ethnic Variations in Risk Factor Profile, Pattern and Recurrence of Non-Cardioembolic Ischemic Stroke; Archives of Medical Research; Volume 37, Issue 5, July 2006, Pages 655-662.

29. Hamilton M, Pickering GW, Fraser Roberts JA, Sowry GS. The etiology of essential hypertension. The role of inheritance. Clin Sci 1954; 13:273-304.

30. Miller JZ, Grim CE. Heritability of blood pressure. In: Kotchen TA, Kotchen JM, (eds). Clinical Approaches to High Blood Pressure in the Young. John Wright. PSG Inc. Littleton, Massachusetts, 19;79-80

31. Malik M, Bakir A, Saab BA, King H. Glucose intolerance and associated factors in the multi-ethnic population of the United Arab Emirates: results of a national survey. Diabetes Res Clin Pract. 2005 Aug;69(2):188-95.

32. Guo, Yanjun; Liu, Yuewei; Huang, Xiji; Rong, Yi; He, Meian; et al. PLoS One 8.8 (Aug 2013). The Effects of Shift Work on Sleeping Quality, Hypertension and Diabetes in Retired Workers: e71107.

33. El-Hazmi MA, Warsy AS. Prevalence of overweight and obesity in diabetic and non-diabetic Saudis. East Mediterr Health J. 2000 Mar-May;6(2-3):276-82.

34. Evelyn P. Davila PhD, MPH1,2, *, Hermes Florez MD, PhD1,3, Mary Jo Trepka MD, MSPH2, Lora E. Fleming MD, $\mathrm{PhD} 1$, Theophile Niyonsenga PhD2, David J. Lee PhD1, Jai Parkash PhD4 Long work hours is associated with suboptimal glycemic control among US workers with diabetes. American Journal of Industrial Medicine Volume 54, Issue 5, pages 375383, May 2011.

35. Alberti KG, Zimmet $P$ and Shaw J. The metabolic syndrome--a new worldwide definition. Lancet 2005; 366: 1059-62.

36. http://www.acponline.org/about_acp/chapters/al/13mtg/culpepper.pdf. Accessed online on 20.02.2015

37. Minicuci N1, Biritwum RB2, Mensah G2, Yawson AE2, Naidoo N3, Chatterji S3, Kowal P4.Sociodemographic and socioeconomic patterns of chronic non-communicable disease among the older adult population in Ghana. Glob Health Action. 2014 Apr 15;7:21292. doi: 10.3402/gha.v7.21292. eCollection 2014.

38. Hamilton M, Pickering GW, Fraser Roberts JA, Sowry GS. The etiology of essential hypertension. The role of inheritance. ClinSci 1954; 13:273-304.
39. Miller JZ, Grim CE. Heritability of blood pressure. In: Kotchen TA, Kotchen JM, (eds). Clinical Approaches to High Blood Pressure in the Young. John Wright. PSG Inc. Littleton, Massachusetts, 19;79-80.

40. Van der Sande Marianne A.B., Walraven Gijs E.L., Milligan Paul J.M., Banya Winston A.S., Ceesay Sana M., Nyan Ousman A. et al . Family history: an opportunity for early interventions and improved control of hypertension, obesity and diabetes. Bull World Health Organ [serial on the Internet]. 2001 Jan [cited 2015 Feb 18] ; 79( 4 ): 321-328. Available from: http:// www.scielosp.org/scielo.php?script=sci_arttext\&pid=S004296862001000400009\&lng=en. http://dx.doi.org/10.1590/ S0042-96862001000400009.

41. M Alquaiz, R Siddiqui, H Qureshi, A Fouda, A Almuneef, A Habib, M Turkistani.Women Health in Saudi Arabia: A review of non-communicable diseases and their risk factors. Pak J Med Sci. 2014 Mar;30(2):422-431.

42. Moosazadeh, Ziaaddini, Mirzazadeh, Ashrafi-Asgarabad, Haghdoost.Meta-analysis of Smoking Prevalence in Iran. Addict Health. 2013 Summer-Autumn;5(3-4):140-53.

43. Mohan V, Shanthirani CS, Deepa R.; Glucose intolerance (diabetes and IGT) in a selected South Indian population with special reference to family history, obesity and lifestyle factors--the Chennai Urban Population Study (CUPS 14); J Assoc Physicians India. 2003 Aug;51:771-7.

44. Shailendra Kumar Tripathi, B. P. Mishra1, Ruchi Tripathi, M. Mishra , K. Tripathi; Comparative Study Of Vegetarian And Non-Vegetarian Diet On Blood Pressure, Serum Sodium And Chloride From Two Different Geographical Locations; Indian J. Prev. Soc. Med. Vol. 41 No.3 and 4, Jul-Dec 2010

45. Pérez CM1, Soto-Salgado M, Suárez E, Guzmán M, Ortiz AP.High Prevalence of Diabetes and Prediabetes and Their Coexistence with Cardiovascular Risk Factors in a Hispanic Community. J Immigr Minor Health. 2014 Apr 30. [Epub ahead of print]

46. Jones DH1, Nestore M2, Henophy S2, Cousin J2, Comtois AS3. Increased cardiovascular risk factors in breast cancer survivors identified by routine measurements of body composition, resting heart rate and arterial blood pressure. Springerplus. 2014 Mar 19;3:150. doi: 10.1186/2193-1801-3-150. eCollection 2014.

47. Napoli N1, Shah K, Waters DL, Sinacore DR, Qualls C, Villareal DT. Effect of weight loss, exercise, or both on cognition and quality of life in obese older adults. Am J Clin Nutr. 2014 Apr 30. [Epub ahead of print]

48. Mandal A. Study of Prevalence of Type 2 Diabetes Mellitus and Hypertension in Overweight and Obese People. J Family Med Prim Care. 2014 Jan;3(1):25-8. doi: 10.4103/22494863.130265.

49. Pan B1, Chen X1, Wu X1, Li J2, Li J2, Li Y3, Hao X3, Liu H4. Prevalence of non-communicable diseases and their risk factors in Guangzhou, china. Prev Chronic Dis. 2014 Mar 27;11:E49. doi: 10.5888/pcd11.130091.

50. Rahim HF1, Sibai A2, Khader Y3, Hwalla N4, Fadhil I5, Alsiyabi H6, Mataria A5, Mendis S7, Mokdad AH8, Husseini A9. Non-communicable diseases in the Arab world. Lancet. 2014 Jan 25;383(9914):356-67. doi: 10.1016/S0140-6736(13)623831. Epub 014 Jan 20. 